\title{
Aplicação da técnica de oxidação química in situ com permanganato de potássio para a remediação de um aquífero raso contaminado por solventes clorados
}

\author{
Application of in situ chemical oxidation technique with potassium permanganate for the \\ remediation of a shallow aquifer contaminated with chlorinated solvents
}

\author{
Alaine Santos da Cunha ${ }^{1}$ e Reginaldo Antonio Bertolo ${ }^{2}$ \\ ${ }^{1}$ Geóloga autônoma, Rua Poetisa Colombina 141, Jardim Bonfiglioli, CEP 05593-010, São Paulo, SP, BR \\ (alainecunha@yahoo.com.br) \\ ${ }^{2}$ Centro de Pesquisas de Águas Subterrâneas, Instituto de Geociências, Universidade de São Paulo - USP, São Paulo, SP, BR \\ (bertolo@usp.br)
}

Recebido em 07 de março de 2012; aceito em 08 de agosto de 2012

\begin{abstract}
Resumo
A oxidação química in situ é um método de remediação que vem sendo empregado em áreas contaminadas de forma cada vez mais frequente, por apresentar uma eficiência satisfatória na redução da massa de contaminantes, particularmente etenos clorados, durante um período de tempo relativamente curto. Este artigo apresenta os resultados da aplicação da técnica de oxidação química com injeção de permanganato de potássio para a remediação de uma área impactada por compostos organoclorados, principalmente o 1,1-dicloroeteno. A efetividade deste método de remediação está relacionada com a complexidade do modelo conceitual da contaminação e com a realização de estudos específicos em laboratório e em escala de teste-piloto no campo, antes propriamente da realização das atividades em escala de remediação. Neste sentido, este trabalho contribui apresentando uma descrição dos procedimentos que são utilizados para a realização de estudos desta natureza. No caso em estudo, estimou-se que o 1,1-dicloroeteno teve sua massa reduzida de 15,53 para 1,81 kg no aquífero, após 22 meses da realização das atividades de aplicação do agente oxidante em nível de remediação. As concentrações médias na água subterrânea foram reduzidas de 200 para $24 \mu \mathrm{g} / \mathrm{L}$, sendo esta inferior ao limite do padrão ambiental e à meta de remediação calculada por avaliação de risco. Repiques significativos da contaminação não foram identificados no local após a injeção do oxidante químico. Foi avaliado que o resultado favorável da remediação neste caso pode estar relacionado pela associação da baixa heterogeneidade relativa do aquífero com as baixas concentrações originais do contaminante.
\end{abstract}

Palavras-chave: Aquífero; Áreas contaminadas; Remediação; Oxidação química in situ.

\begin{abstract}
In situ chemical oxidation is a method that is frequently being used for the remediation of contaminated areas, since it presents an adequate efficiency in the reduction of the contaminant mass, particularly chlorinated ethenes, in a relatively short period of time. This manuscript presents the results of the application of this method, using the injection of potassium permanganate as the remediation agent, in an impacted area with chlorinated organic compounds, especially 1,1-dichloroethene. The effectiveness of this remediation method is related to the complexity of the conceptual model of the contaminated site and to the conduction of specific studies in laboratory and pilot tests in field scale, prior to the accomplishment of the full-scale remediation. Therefore, this work contributes presenting a description of the procedures that are commonly used for conducting this kind of studies. In the case under study, it was estimated that the mass of 1.1-dichloroethene (1.1-DCE) was reduced from 15.53 to $1.81 \mathrm{~kg}$ in groundwater 22 months after the injection of potassium permanganate in the aquifer. The average concentrations of 1.1-DCE in groundwater decreased from 200 to $24 \mu \mathrm{g} / \mathrm{L}$, which value is lower than the environmental standard limit and also to the calculated target of remediation based on human-health risk assessment. Significant contamination rebounds were not identified in the aquifer after the injection of the chemical oxidant. The suitable results of the remediation in this case may be related to the relatively low aquifer heterogeneity and low original concentrations of the contaminant.
\end{abstract}

Keywords: Aquifer; Contaminated sites; Remediation; In situ chemical oxidation. 


\section{INTRODUÇÃO}

Os solventes organoclorados, especialmente os etenos e etanos clorados, possuem elevada eficiência como desengraxantes, sendo utilizados de forma intensiva por diversos segmentos industriais desde o início de sua fabricação em larga escala. A partir do final da década de 1960, entretanto, tais compostos começaram a ser apontados como um dos principais causadores de contaminação em subsuperfície. Quando presentes na água subterrânea, mesmo em concentrações na ordem de partes por bilhão, tornam-na imprópria para consumo, trazendo potencial risco à saúde humana e ao meio ambiente (Pankow e Cherry, 1996).

Embora os contaminantes organoclorados possam ser degradados naturalmente, estes processos são, em geral, lentos, tornando necessária a adoção de medidas para a aceleração da destruição destes compostos químicos em situações de risco ambiental. Os processos de degradação de natureza química abiótica geralmente tendem a ser mais viáveis e mais adequados para a reabilitação de uma área impactada, para que potenciais riscos possam ser anulados ou gerenciados de maneira mais eficiente.

A oxidação química in situ (in situ chemical oxidation - ISCO) pode ser utilizada como uma alternativa eficaz de remediação, quando os contaminantes organoclorados estiverem presentes no solo saturado ou na franja capilar nas fases dissolvida e adsorvida. Em locais onde é necessário o tratamento de área fonte na zona não saturada, o mais indicado é que outra tecnologia de remediação seja requerida, como por exemplo, a extração de vapores do solo. Na existência de produto em fase livre e residual, outras tecnologias de remediação precisam ser conduzidas anteriormente à oxidação química para que a remediação seja eficiente, segura e de custo viável (USEPA, 2006).

Este artigo objetivou apresentar os resultados da aplicação do método ISCO a partir do uso de permanganato de potássio $\left(\mathrm{KMnO}_{4}\right)$ como agente oxidante, em uma área industrial cujo aquífero raso apresentava-se contaminado por compostos orgânicos voláteis, sendo o composto 1,1 dicloroeteno (1,1-DCE) o principal alvo. Durante o processo de remediação química do aquífero raso na área, procurou-se garantir que as seguintes condições fossem atendidas: que o oxidante aplicado tivesse conseguido entrar em contato com o contaminante em toda a área e profundidade da pluma de contaminação; e que a quantidade de oxidante tivesse sido suficiente para destruir os contaminantes até a meta de remediação. O composto oxidante foi injetado em um aquífero freático relativamente homogêneo, situado num contexto geológico de manto de intemperismo desenvolvido sobre rochas sedimentares do membro inferior da Formação Tatuí (Bacia do Paraná).

Como os processos de advecção e dispersão são fundamentais para o aumento da eficiência da ação do permanganato de potássio como agente oxidante, de forma que este alcance o contaminante presente nas fases dissolvidas e adsorvidas, é importante que o aquífero possua algumas características, tais como:

- elevadas condutividade hidráulica e velocidade da água subterrânea, permitindo que o oxidante alcance áreas maiores para contato com o contaminante;

- elevada homogeneidade relativa, pois a eficiência do oxidante em entrar em contato com o contaminante pode ser comprometida em aquíferos heterogêneos e pouco permeáveis (Seol, Zhang, Schwartz, 2003), impossibilitando a distribuição uniforme do fluido;

- baixa concentração relativa de compostos inorgânicos oxidáveis, pois a presença de compostos oxidáveis de ferro ferroso e outros metais formam precipitados que poderiam reduzir significativamente a permeabilidade intrínseca da zona saturada e competir com o contaminante no processo de oxidação (USEPA, 2004); e

- reduzido índice de carbono orgânico oxidável, pois sua presença pode consumir parte importante do agente oxidante injetado e tornar a alternativa economicamente inviável (Suthersan e Payne, 2005).

Segundo Crimi e Siegrist (2003), as reações entre o $\mathrm{KMnO}_{4}$ e os solventes organoclorados, tetracloroeteno (PCE), tricloroeteno (TCE), dicloroeteno (DCE) e cloreto de vinila (VC), são apresentadas, respectivamente, pelas Equações 1 a 4:

- $4 \mathrm{KMnO}_{4}+3 \mathrm{C}_{2} \mathrm{Cl}_{4}+4 \mathrm{H}_{2} \mathrm{O} \rightarrow 6 \mathrm{CO}_{2}+4 \mathrm{MnO}_{2}+$ $4 \mathrm{~K}^{+}+8 \mathrm{H}^{+}+12 \mathrm{Cl}^{-}$

- $2 \mathrm{KMnO}_{4}+\mathrm{C}_{2} \mathrm{HCl}_{3} \rightarrow 2 \mathrm{CO}_{2}+2 \mathrm{MnO}_{2}+2 \mathrm{~K}^{+}+$ $\mathrm{H}^{+}+3 \mathrm{Cl}^{-}$

- $8 \mathrm{KMnO}_{4}+3 \mathrm{C}_{2} \mathrm{H}_{2} \mathrm{Cl}_{2} \rightarrow 6 \mathrm{CO}_{2}+8 \mathrm{MnO}_{2}+8 \mathrm{~K}^{+}+$ $6 \mathrm{Cl}^{-}+2 \mathrm{OH}^{-}+2 \mathrm{H}_{2} \mathrm{O}$

- $10 \mathrm{KMnO}_{4}+3 \mathrm{C}_{2} \mathrm{H}_{3} \mathrm{Cl} \rightarrow 6 \mathrm{CO}_{2}+10 \mathrm{MnO}_{2}+$ $10 \mathrm{~K}^{+}+3 \mathrm{Cl}^{-}+7 \mathrm{OH}^{-}+\mathrm{H}_{2} \mathrm{O}$

O principal reagente na oxidação do contaminante orgânico é o íon permanganato $\left(\mathrm{MnO}_{4}^{-}\right)$, que possui valência +7 (Mn(VII)). Durante a reação, o Mn(VII) é reduzido para $\mathrm{Mn}(\mathrm{IV})$, que rapidamente se precipita como dióxido de manganês (Suthersan e Payne, 2005). O permanganato tem grande afinidade na oxidação de compostos contendo cadeias de carbono de ligação dupla, grupos dos aldeídos e das hidroxilas. Sob condições normais de $\mathrm{pH}$ e temperatura, a ligação dupla das cadeias de carbono dos alcenos é quebrada espontaneamente, e compostos intermediários instáveis são convertidos em dióxido de carbono $(\mathrm{Hu}$ e Chou, 2002). Além do dióxido de carbono, são também resultados da reação: sólidos de dióxido de manganês e íons de potássio e cloreto (quando compostos halogenados são oxidados), que em geral não são tóxicos à saúde 
humana nas quantidades geradas durante a remediação (DOE, 1999).

A avaliação correta da dosagem de $\mathrm{KMnO}_{4}$ é um passo importante na escolha desta alternativa como tratamento de um meio contaminado por compostos organoclorados, e é obtida pela demanda de oxidante do solo (SOD) ou na demanda natural de oxidante (NOD). A SOD ou NOD é a quantidade de oxidante consumido por unidade de massa sólida do aquífero em determinado tempo. A eficácia da oxidação de contaminantes organoclorados até sua completa mineralização é inversamente proporcional à presença natural de matéria orgânica, ferro ferroso (FeII) e outros metais encontrados na forma reduzida em minerais do meio poroso. Isto porque, durante o processo de oxidação, o permanganato de potássio reage igualmente com os contaminantes e com os compostos orgânicos naturais e inorgânicos oxidáveis presentes no meio poroso (Hønning, 2007).

Entre as principais vantagens para a aplicação da ISCO como metodologia de remediação, tem-se: 1) assim que injetado, $\mathrm{o} \mathrm{KMnO}_{4}$ está prontamente disponível para a reação com os contaminantes e resulta na geração de produtos geralmente inócuos; 2) o íon permanganato é relativamente estável e possui meia-vida longa, o que favorece a maior probabilidade do reagente de entrar em contato com o contaminante no aquífero; 3 ) o processo tem aplicação e controle relativamente simples; 4 ) os tempos de tratamento e reação são relativamente rápidos; e 5) não há geração de resíduos (DOE, 1999). Ainda como vantagens podem ser apontadas a rápida e intensa reação dos agentes oxidantes na diminuição das concentrações dos contaminantes (incluindo compostos biorrecalcitrantes) e a facilidade de uso e adaptação de equipamentos e materiais que compõem o sistema (Crimi e Siegrist, 2003).

Como desvantagens, podem ser citadas (USEPA, 2006; Hu e Chou, 2002): a demanda de oxidante pode ser elevada e proibitiva em aquíferos com elevada NOD; as alterações na geoquímica natural do aquífero, com a possível mobilização de metais tóxicos; a redução da permeabilidade do aquífero devido à precipitação de sólidos de dióxido de manganês $\left(\mathrm{MnO}_{2}\right)$, especialmente em áreas com suspeita de ocorrência de fase livre e/ou residual; e a maior probabilidade de ocorrência de repiques de contaminação em aquíferos muito heterogêneos após as atividades de remediação, devido ao fenômeno de difusão reversa dos contaminantes a partir dos poros de estratos de baixa permeabilidade.

\section{ÁREA DE ESTUDO}

A área de estudo encontra-se a cerca de $150 \mathrm{~km}$ a Noroeste da Região Metropolitana de São Paulo, e foi utilizada entre 1990 e 1998 como local de estocagem temporária de tambores com resíduos gerados no setor de produção de uma fábrica de peças automotivas e como área de lavagem de veículos. Tais resíduos eram principalmente efluentes oriundos da área de lavagem e desengraxe das peças.

\section{Geologia e hidrogeologia}

A área está inserida na borda leste da Bacia do Paraná, onde regionalmente são identificadas as Formações Corumbataí, Irati, Tatuí e Grupo Itararé (IPT, 1981). A partir das descrições geológicas realizadas durante perfurações do solo para instalação dos poços de monitoramento, foram identificados três níveis de características distintas, sendo o primeiro classificado como aterro, devido à presença de areia de fundição e material de corte do próprio terreno, e os demais, respectivamente, como manto de intemperismo e rocha pouco alterada. As características deste material indicam correlação com as litologias referentes ao membro inferior da Formação Tatuí (Barbosa e Gomes, 1958; Soares, 1972).

A Figura 1 apresenta uma seção esquemática da estratigrafia encontrada na área. $\mathrm{O}$ nível superior do manto de intemperismo é composto por silte argiloso com presença de

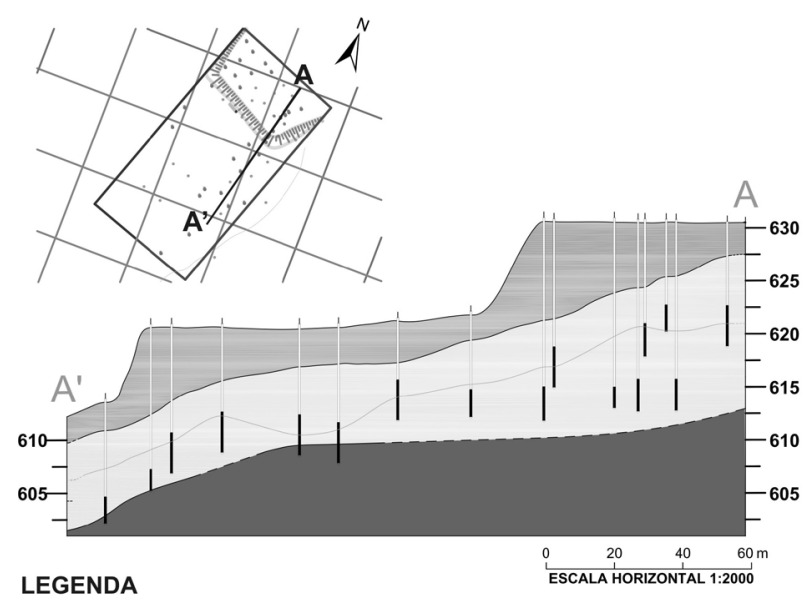

Aterro: areia fina com matriz pouco argilosa, friável, coloração bege acinzentada (areia de fundição)

Manto de Intemperismo: silte argiloso, com areia fina presença de lentes argilosas, laminado, coloração com porções branca a roxa, vermelha e cinza amarelada

Rocha: siltito, compacto, roxo

Nível D'Água

Contato Inferido

Figura 1. Seção hidrogeológica da área de estudo. 
níveis de areia fina, estruturas de laminação, alta plasticidade e colorações branca, roxa, vermelha, cinza e amarela. A seguir, observou-se um siltito menos intemperizado, de alta compacidade e coloração roxa. Esta camada de siltito, identificada como aquitarde, foi considerada como uma barreira natural e, portanto, perfurações que pudessem ultrapassá-la não foram consideradas para evitar uma possível mobilização dos contaminantes presentes no aquífero freático para níveis mais profundos.

De modo geral, a área da pluma de contaminação ocorre em uma meia-encosta, que corresponde à área de recarga do aquífero freático local (Figura 2). No limite sul, encontra-se a principal área de descarga da área de estudo,

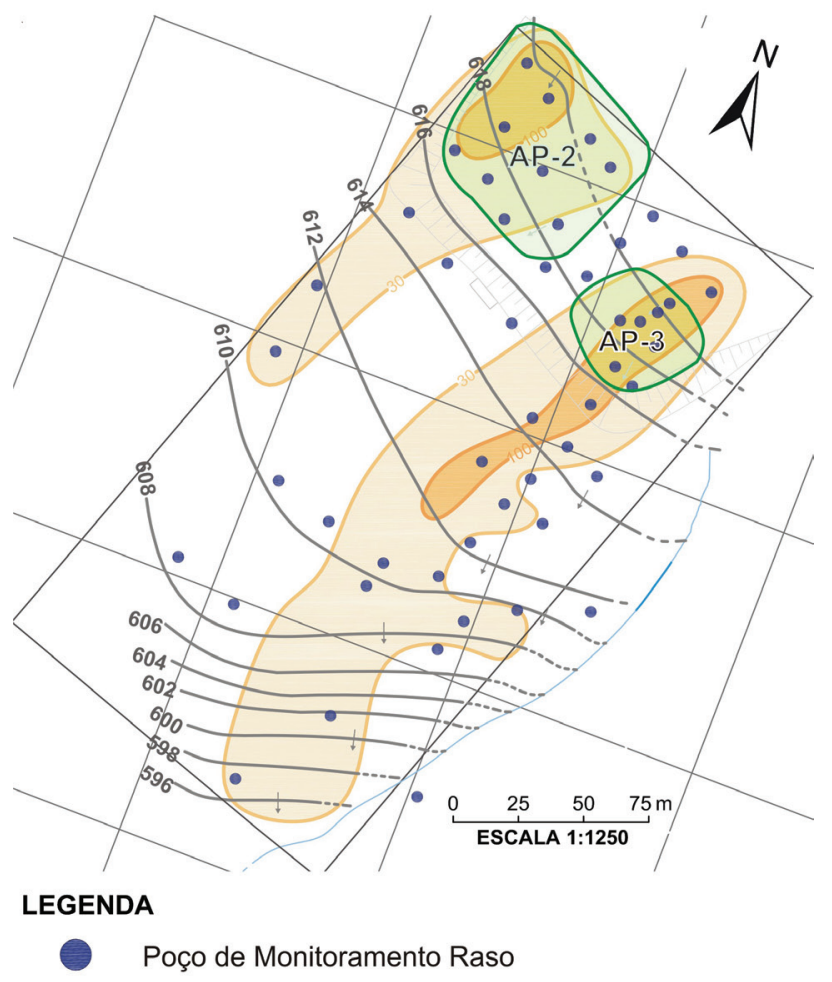

596,00 -- Linhas Equipotenciais (metros)

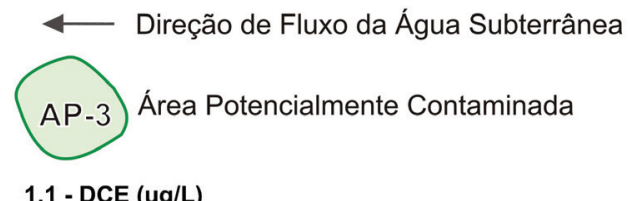

1,1 - DCE (ug/L)

$30-100$

$>100$

DCE: dicloroeteno.

Figura 2. Mapa potenciométrico do aquífero freático e configuração da pluma de contaminação de 1,1-dicloroeteno antes da injeção do oxidante em toda a área (situação em março de 2008). um corpo de água intermitente de direção NE-SW. O mapa potenciométrico do local (Figura 2), obtido com dados de março de 2008, indica que a direção preferencial do fluxo da água subterrânea é N-S, com elevados valores de gradiente hidráulico. As cargas hidráulicas obtidas nos poços de monitoramento multiníveis, instalados em profundidades distintas do aquífero freático, indicam a existência de um potencial vertical descendente para o fluxo da água subterrânea no local.

Testes hidráulicos realizados em seis poços de monitoramento existentes na área apresentaram valores de condutividade hidráulica variando entre $8,65 \times 10^{-5} \mathrm{~cm} / \mathrm{s}$ (poço localizado no limite noroeste) e $1,06 \times 10^{-4} \mathrm{~cm} / \mathrm{s}$ (no limite sudeste). De acordo com os valores de carga hidráulica obtidos, calculou-se uma velocidade potencial média do fluxo da água subterrânea de $30 \mathrm{~m} / \mathrm{ano}$. Segundo a United States Environmental Protection Agency - USEPA (2006), locais que apresentem valores de condutividade hidráulica superiores a $1,00 \times 10^{-7} \mathrm{~cm} / \mathrm{s}$ podem ser considerados apropriados para a aplicação de tecnologias de remediação que envolvam injeção de fluidos no aquífero.

\section{Características da contaminação}

Cerca de 20.000 tambores contendo resíduos provenientes do tratamento químico de materiais (galvanoplastia) e do desengraxe de peças produzidas na fábrica foram dispostos no nível superior da área de estudo (AP-2), a Noroeste do terreno (Figura 2). Uma segunda área potencialmente contaminada (AP-3), responsável pela contaminação de solventes clorados na água subterrânea do aquífero freático, encontrada a Nordeste do terreno, envolvia atividades relacionadas à lavagem de veículos.

Apesar de os produtos solventes originais, como tetracloroeteno (PCE), tricloroeteno (TCE) e 1,1,1-tricloroetano (1,1,1-TCA) terem sido estocados e manipulados na área, é o produto filho 1,1-dicloroeteno (1,1-DCE), gerado pela degradação natural dos solventes utilizados, que aparece como o principal composto de interesse na água subterrânea neste caso. A Figura 2 apresenta a configuração da pluma de 1,1-DCE identificada na campanha de monitoramento de abril de 2008, anterior às atividades de remediação aplicadas na área contaminada.

Os primeiros indícios de contaminação da água subterrânea foram observados em 1997, quando ocorreu a primeira investigação ambiental na área. A partir de então, 52 poços de monitoramento foram instalados nesta área para identificar e delimitar a área impactada. Com a finalidade de se checar a possibilidade de existência de fase livre não-aquosa densa, poços de monitoramento multiníveis foram instalados, tanto no nível superior (entre 8 e $12 \mathrm{~m}$ de profundidade) quanto inferior do aquífero freático (entre 15 e $21 \mathrm{~m}$ de profundidade), no qual é iniciado o topo 
da camada do aquitarde. Como mencionado, esta camada, de característica hidráulica de baixa permeabilidade, limitou as atividades de investigação.

Uma avaliação de risco à saúde humana foi realizada para esta área em 2003, resultando que o composto 1,1DCE era o principal contribuinte para o risco potencial da inalação de vapores provenientes da volatilização deste contaminante presente na água subterrânea em ambientes fechados para os trabalhadores existentes na área. Baseada nesta circunstância, foi obtida a meta de remediação de $290 \mu \mathrm{g} / \mathrm{L}$ para tal composto. A maior concentração detectada de 1,1-DCE na água subterrânea $(880 \mu \mathrm{g} / \mathrm{L})$ foi identificada na campanha de monitoramento de maio de 2005.

Por conta dos resultados encontrados nas etapas de investigação e na avaliação de risco, foi necessária a consideração de medidas de remediação para redução das concentrações dos contaminantes presentes na porção mais impactada do aquífero freático. Para a implantação da metodologia de remediação, foram considerados os critérios de eficácia, implementabilidade técnica, restrições de tempo, aceitação do órgão ambiental e custo.

Assim, uma série de atividades envolvendo ensaios técnicos em campo e em laboratório foram necessários para avaliar se a metodologia de remediação pela oxidação química in situ seria a mais adequada para o tratamento dos contaminantes presentes nas fases dissolvida e adsorvida.

\section{MÉTODOS}

A condução de atividades que visem à reabilitação de uma área contaminada pela aplicação de técnicas químicas destrutivas de contaminantes deve ser embasada por conhecimentos práticos de como o aquífero responderá hidráulica e geoquimicamente à injeção de reagentes em seu interior. Assim, resultados de ensaios realizados em campo e em laboratório, assim como aqueles de um teste-piloto de remediação, foram avaliados antes da execução das atividades de remediação química da pluma de contaminação propriamente dita.

\section{Ensaios em campo e em laboratório}

Os ensaios em campo e em laboratório foram conduzidos com o objetivo de trazer respostas quanto ao comportamento hidráulico do aquífero frente à injeção de fluido e às características da contaminação e do meio em que estão inseridas.

\section{Teste de injeção de água}

Um teste de injeção de água foi realizado visando avaliar a efetividade hidráulica do aquífero freático em transportar o reagente de forma apropriada no seu interior. Para conduzir o teste, foram instalados dois poços de injeção a jusante da pluma presente a Nordeste da área. Os poços foram construídos com a profundidade de $15 \mathrm{~m}$, na qual foi identificado o topo da camada do aquitarde (siltito). Os procedimentos de instalação destes poços encontram-se de acordo com o que é descrito na Norma Brasileira NBR 1595-1 (ABNT, 2007) aplicada para poços de monitoramento, exceto pelo fato de a seção filtrante ser totalmente penetrante no aquífero freático (início da seção filtrante onde o nível saturado foi identificado, neste caso a $7 \mathrm{~m}$ de profundidade). O objetivo da instalação de poços de injeção com esta seção filtrante foi o de facilitar o contato do oxidante com o contaminante em todo nível saturado onde a contaminação foi identificada.

O teste de injeção de água consistiu na injeção de água captada do abastecimento público da região pelo período de seis horas contínuas com carga constante, utilizando-se de um reservatório de água de $2.000 \mathrm{~L}$ para tal. O teste em cada um dos poços de injeção foi realizado em dias diferentes, após a verificação do retorno do nível estático do aquífero para a profundidade identificada antes do início dos testes, de forma a evitar interferências nos resultados. Em cada um dos testes de injeção, 11 poços de monitoramento existentes até $57 \mathrm{~m}$ de distância foram monitorados para avaliar a variação do nível d'água durante as seis horas de injeção. Os resultados deste teste permitiram avaliar o potencial raio de influência inicial de injeção.

\section{Análises químicas de solo}

Amostras de solo saturado foram coletadas em três pontos distintos da área contaminada em profundidades variando entre 7 e $12 \mathrm{~m}$ para análises químicas de ferro total, carbono orgânico total e de SOD. Essas análises visam determinar as características específicas do solo e a eficiência do uso de oxidante. Para a análise de SOD, uma solução de concentração conhecida de $\mathrm{KMnO}_{4}$ é adicionada a uma quantidade específica de solo contaminado por um período de 48 horas. Decorrido o período de reação, determinam-se as concentrações do permanganato residual extraído da solução e calcula-se o SOD pela diferença das concentrações iniciais e finais do permanganato (ASTM, 2010).

Amostras de solo foram também coletadas e enviadas a um laboratório para análise de tratabilidade, que corresponde a uma avaliação da efetividade do permanganato de potássio em ser um composto favorável para a oxidação eficiente dos contaminantes presentes na amostra.

\section{Injeção do oxidante em escala de teste-piloto}

Devido ao elevado custo envolvido na aplicação de uma metodologia de remediação, é importante que seja 
primeiramente realizado um teste em uma área de dimensões limitadas, as quais representem as características do meio e da contaminação como um todo para avaliar se o método de remediação é eficaz na escala de campo. As técnicas aplicadas no teste-piloto devem ser semelhantes à que potencialmente será empregada, posteriormente, em toda a área.

O local que apresentava as maiores concentrações de 1,1-DCE foi selecionado para a aplicação da ISCO como teste-piloto (centro da pluma de contaminação a Nordeste da área). Com base no raio de influência inicial identificado a partir dos resultados do teste de injeção de água, foram instalados sete poços de injeção de perfil construtivo semelhante ao descrito anteriormente, e com profundidades variando entre 18 e $20 \mathrm{~m}$, nos quais foi identificado o topo da camada de aquitarde.

Para dimensionar a área impactada que seria primeiramente tratada neste teste-piloto, foi necessário verificar as características específicas da área de estudo. Desta forma, com base nas informações levantadas em testes e análises anteriores, foram obtidos: o volume de solo saturado impactado (Equação 5); o coeficiente de distribuição do contaminante (Equação 6); a concentração média adsorvida no solo (Equação 7); a massa de contaminante adsorvida na matriz sólida do aquífero (Equação 8); o volume efetivo de solo contaminado que entrará em contato com o oxidante por poço de injeção (Equação 9); a massa de oxidante necessária para o tratamento da área do teste-piloto (Equação 10) e a concentração do oxidante utilizado na solução (Equação 11).

- $\mathrm{V}=\mathrm{A} \cdot \mathrm{h}$

- $\mathrm{K}_{\mathrm{d}}=\mathrm{K}_{\mathrm{oc}} \cdot \mathrm{f}_{\mathrm{oc}}$

- $\mathrm{C}_{\mathrm{s}}=\mathrm{K}_{\mathrm{d}} \cdot \mathrm{C}_{\mathrm{a}}$

- $\mathrm{M}_{\mathrm{s}}=\mathrm{V} \cdot \rho \cdot \mathrm{C}_{\mathrm{s}} \cdot 10^{-3}$

- $\mathrm{V}_{\mathrm{e}}=\pi \cdot \mathrm{R}^{2} \cdot \mathrm{h} \cdot \mathrm{n}_{\mathrm{e}}$

- $\mathrm{M}_{\mathrm{e}}^{\mathrm{e}}=\mathrm{V} \cdot \rho \cdot \mathrm{SOD}$

- $\mathrm{V}_{\mathrm{as}}=\mathrm{M}_{\mathrm{o}} / \mathrm{C}_{\mathrm{o}}$

onde,

- A: área impactada $\left(\mathrm{m}^{2}\right)$;

- V: volume de solo saturado contaminado $\left(\mathrm{m}^{3}\right)$;

- h: espessura saturada contaminada do aquífero (m);

- $\mathrm{K}_{\mathrm{d}}$ : coeficiente de distribuição ou de partição $(\mathrm{mg} / \mathrm{g})$;

- $\mathrm{K}_{\mathrm{oc}}$ : coeficiente de partição de carbono orgânico $(\mathrm{mg} / \mathrm{g})$;

- $\mathrm{f}_{\mathrm{c}}$ : fração de carbono orgânico contida no solo (\%);

- $\mathrm{C}_{\mathrm{a}}$ : concentração média dissolvida na água subterrânea $(\mathrm{mg} / \mathrm{L})$;

- $\mathrm{C}_{\mathrm{s}}$ : concentração média adsorvida no solo $(\mathrm{mg} / \mathrm{kg})$;

- $\rho:$ densidade do solo $\left(\mathrm{g} / \mathrm{cm}^{3}\right)$;

- $\mathrm{M}_{\mathrm{s}}$ : massa de contaminante no solo saturado $(\mathrm{kg})$;

- R: raio de influência por poço de injeção (m);
- $\mathrm{V}_{\mathrm{e}}$ : volume efetivo de solo contaminado que tem contato com o oxidante por poço de injeção $\left(\mathrm{m}^{3}\right)$;

- $\mathrm{n}_{\mathrm{e}}$ : porosidade efetiva (\%);

- SOD: demanda de oxidante no solo $\left(\mathrm{g} \mathrm{KMnO}_{4} / \mathrm{kg}\right.$ solo);

- $\mathrm{M}_{\mathrm{o}}$ : massa de oxidante $(\mathrm{kg})$;

- $\mathrm{C}_{\mathrm{o}}$ : concentração do oxidante (\%);

- $\mathrm{V}_{\mathrm{as}}$ : volume de água para solução (L).

Com o conhecimento da dosagem e do volume da solução de permanganato de potássio ideais para a realização do teste-piloto, partiu-se para a instalação do sistema de injeção (tanques e bombas), que foi instalado em uma bacia de contenção de concreto. A solução foi preparada em um tanque de mistura de $1 \mathrm{~m}^{3}$ e encaminhada a dois tanques de $10 \mathrm{~m}^{3}$ para posterior injeção.

A tubulação e os equipamentos do sistema de injeção foram construídos em PVC e em polietileno de alta densidade (PEAD), por apresentarem compatibilidade química com o permanganato de potássio, evitando deterioração das peças em contato com a solução injetada pela oxidação. Os poços de injeção e de monitoramento nas proximidades foram constantemente monitorados para evitar excesso de pressão, o que poderia causar vazamentos da solução nas linhas e nos poços de injeção e afloramento do nível d'água causado pelo volume injetado. Para que fossem evitados danos aos eletrodos dos equipamentos portáteis, os parâmetros físico-químicos temperatura, $\mathrm{pH}$, potencial redox, condutividade elétrica e oxigênio dissolvido, não foram obtidos da água subterrânea daqueles poços de monitoramento, nos quais notou-se a presença do permanganato de potássio.

Para avaliar a eficiência da ação do permanganato frente ao contaminante presente no meio, amostras de água subterrânea foram coletadas e analisadas para os etanos e etenos clorados de interesse. A avaliação geoquímica da área foi comprometida, já que não foi possível para o laboratório a realização de análises químicas para avaliação das concentrações de metais dissolvidos na água subterrânea, devido à presença de permanganato de potássio, que poderia provocar danos aos equipamentos analíticos.

Como procedimento de amostragem, a água subterrânea coletada com presença de permanganato de potássio para análise de VOC foi neutralizada com tiosulfato de sódio para que as características da contaminação fossem representativas do momento da coleta, mas para isso não puderam ser preservadas com $\mathrm{HCl}$, apenas refrigeradas até a entrega no laboratório para a análise.

\section{Injeção do oxidante em escala de remediação}

A implantação do sistema de remediação ISCO em toda a área contaminada foi realizada de forma semelhante ao 
do teste-piloto, com a instalação de poços de injeção; a injeção do agente oxidante; o monitoramento do comportamento do aquífero freático e os monitoramentos de desempenho do $\mathrm{KMnO}_{4}$ em diminuir as concentrações de 1,1-DCE.

Após avaliação das configurações das plumas de 1,1DCE e as características físico-químicas da área, foram instalados 31 poços de injeção em adição aos nove existentes, com profundidades variando entre 18 e $20 \mathrm{~m}$. Os perfis construtivos destes poços são idênticos aos anteriores, de forma que o oxidante injetado pudesse entrar em contato com o contaminante presente em toda a seção saturada do aquífero freático.

O cálculo completo de dosagem do permanganato de potássio e do volume de solução necessário para que houvesse o maior contato possível do oxidante com o contaminante foi conduzido de acordo com as Equações 5 a 11 .

Durante a etapa de injeção da solução do permanganato, o aquífero freático foi monitorado de forma a identificar a presença do oxidante e a variação do nível de água dos poços de monitoramento. Tais atividades foram realizadas durante o período de injeção e forneceram informações importantes quanto ao real raio de influência do oxidante.

Os monitoramentos para avaliar a eficiência do processo de remediação ocorreram em 1, 3, 6, 15 e 22 meses após a injeção do permanganato. Nestes períodos, foram coletadas amostras de água subterrânea para análises químicas de compostos etenos e etanos clorados e metais dissolvidos, para indicar, respectivamente, o abatimento da massa de contaminante e a possível mobilização de compostos presentes naturalmente no meio. Assim como o ocorrido durante o teste-piloto, nos poços de monitoramento em que a presença de permanganato de potássio foi observada, a coleta de amostras para análise não foi possível, assim como também não foram realizadas medições dos parâmetros físico-químicos visando a não danificação dos aparelhos.

\section{APRESENTAÇÃO E DISCUSSÃO DOS RESULTADOS}

\section{Ensaios em campo e em laboratório}

\section{Teste de injeção de água}

Durante o período de injeção, os níveis de água de 11 poços de monitoramento e 2 poços de injeção, utilizados no teste, foram medidos a cada três horas para avaliar o comportamento do aquífero freático, quanto à percolação da água injetada. As variações máxima e mínima do nível d'água dos poços de monitoramento utilizados no teste ao longo das 6 horas de injeção foram de $25 \mathrm{~cm}$, no poço mais próximo a jusante daquele de injeção (a $6,60 \mathrm{~m})$, e $1 \mathrm{~cm}$ no poço situado a $26 \mathrm{~m}$ daquele de injeção, respectivamente.

A variação do nível d'água observada em poços de monitoramento distantes até $18 \mathrm{~m}$ dos poços de injeção, no curto período de seis horas de duração do teste, foi devido à movimentação radial da água subterrânea causada pelo grande volume de água injetado (mais de $6.000 \mathrm{~L}$ de água em cada um dos poços de injeção), e não ao caminhamento real da água injetada até tal distância. Com base na observação da variação do nível d'água entre os poços de injeção e um dos poços de monitoramento, estimou-se que poderia ser assumida a distância de $6,60 \mathrm{~m}$ como raio de influência inicial de injeção.

Além disso, considerou-se que o oxidante acompanha o caminhamento natural do fluxo da água subterrânea após o término do período de injeção. Portanto, por meio dos fenômenos da advecção e dispersão, esperava-se que o oxidante alcançasse uma maior área e, enquanto permanecesse presente no meio, estaria reagindo com os contaminantes orgânicos até seu completo consumo.

\section{Análises químicas de solo}

Os resultados das análises químicas realizadas para identificar a presença de compostos potencialmente oxidáveis no solo saturado, como ferro ferroso e carbono orgânico total, que entrarão em contato com o permanganato de potássio, são apresentados na Tabela 1. São apresentados também os resultados de SOD, que indicaram a dose necessária de aplicação do permanganato de potássio para que compostos orgânicos presentes no solo fossem oxidados.

Segundo os ensaios de tratabilidade conduzidos pelo laboratório, foi comprovada a eficiência do permanganato de potássio em oxidar os contaminantes organoclorados presentes nas fases dissolvida e adsorvida até concentrações aceitáveis pelos padrões de qualidade. Os resultados do ensaio de eficiência do permanganato de potássio em laboratório, juntamente com as características geoquímicas do aquífero e as concentrações muito inferiores ao limite de solubilidade do 1,1-DCE $(3.350 \mathrm{mg} / \mathrm{L})$, indicaram que a concentração de $0,44 \%$ do oxidante seria suficiente para a diminuição das concentrações dos contaminantes organoclorados presentes no meio.

Com base em informações específicas da área, foi possível dimensionar o sistema de remediação a ser aplicado prioritariamente como teste-piloto e, posteriormente, em toda a área impactada pelo contaminante 1,1-DCE.

\section{Injeção do oxidante em escala de teste-piloto}

Os resultados dos ensaios realizados em campo e em laboratório foram importantes para a seleção da ISCO como 
metodologia de remediação aplicável para a área. O teste de injeção de água mostrou que as condições hidráulicas do aquífero poderiam suportar a entrada de fluidos, e os resultados analíticos apontaram para a viabilidade da utilização da oxidação química como alternativa de remediação. Portanto, o teste-piloto foi conduzido na área determinada, de acordo com as informações apresentadas na Tabela 2.
Com base nos cálculos de dimensionamento do sistema de remediação, uma massa de $2.800 \mathrm{~kg}$ de oxidante foi utilizada no teste-piloto. Para a obtenção de uma solução de $0,44 \%$ de concentração de permanganato de potássio, foi necessária a adição de $644 \mathrm{~m}^{3}$ de água, distribuídos em sete poços de injeção, sendo o volume total em cada um deles entre 89 e $96 \mathrm{~m}^{3}$ de solução.

Tabela 1. Resultados das análises químicas de solo, utilizados para aplicação do oxidante químico no aquífero.

\begin{tabular}{ccccc}
\hline Ponto & $\begin{array}{c}\text { Profundidade da } \\
\text { amostra }(\mathrm{m})\end{array}$ & Fe total $(\mathrm{mg} / \mathrm{kg})$ & TOC $(\%)$ & SOD $\left(\mathrm{g} \mathrm{KMnO}_{4} / \mathrm{kg}\right.$ solo) \\
\hline \multirow{3}{*}{ SS-01 } & 7,2 & 5.640 & 1,62 & - \\
& 10,0 & 1.857 & 0,88 & \\
& 12,0 & 1.724 & 0,61 & \multirow{2}{*}{0,29} \\
SS-02 & 7,0 & 907 & 1,44 & \\
& 9,0 & 5.730 & 1,61 & \\
& 11,0 & 50.240 & 2,27 & 0,86 \\
SS-03 & 6,5 & 20.696 & 2,28 & \\
& 7,5 & 15.504 & 1,94 & \\
\hline
\end{tabular}

TOC: carbono orgânico total; SOD: demanda de oxidante do solo.

Tabela 2. Informações necessárias para o cálculo de dimensionamento do sistema de remediação, considerando o centro de massa de uma das plumas de 1,1- dicloroeteno a ser tratada no teste-piloto e para a remediação de toda a área.

\begin{tabular}{lccc}
\hline Dados & $\begin{array}{c}\text { Valores utilizados } \\
\text { no teste-piloto }\end{array}$ & $\begin{array}{c}\text { Valores utilizados } \\
\text { na remediação }\end{array}$ & Unidade \\
\hline $\mathrm{A}=$ área impactada & 818 & 8.140 & $\mathrm{~m}^{2}$ \\
$\mathrm{~V}=$ volume de solo saturado contaminado & 5.726 & 47.260 & $\mathrm{~m}^{3}$ \\
$\mathrm{~h}=$ espessura saturada contaminada do aquífero & 7 & 7 & $\mathrm{~m}$ \\
$\mathrm{~K}_{\mathrm{d}}=$ coeficiente de distribuição ou de partição & 1,03 & 1,03 & $\mathrm{mg} / \mathrm{g}$ \\
$\mathrm{K}_{\mathrm{oc}}=$ coeficiente de partição de carbono orgânico & 65 & 65 & $\mathrm{mg} / \mathrm{g}$ \\
$\mathrm{f}_{\mathrm{oc}}=$ fração de carbono orgânico contida no solo & 1,58 & 1,58 & $\%$ \\
$\mathrm{C}_{\mathrm{a}}=$ concentração média dissolvida na água subterrânea & 0,20 & 0,20 & $\mathrm{mg} / \mathrm{L}$ \\
$\mathrm{C}_{\mathrm{s}}=$ concentração média adsorvida no solo & 0,21 & 0,21 & $\mathrm{mg} / \mathrm{kg}$ \\
$\rho=$ densidade do solo & 1,60 & 1,60 & $\mathrm{~g} / \mathrm{cm}{ }^{3}$ \\
$\mathrm{M}_{\mathrm{s}}=$ massa de contaminante no solo saturado & 1,88 & 15,53 & $\mathrm{~kg}$ \\
$\mathrm{R}=$ raio de influência por poço de injeção & 6 & 6 & $\mathrm{~m}$ \\
$\mathrm{~V}_{\mathrm{e}}=$ volume efetivo de solo contaminado que terá contato & 79,13 & 79,13 & $\mathrm{~m}$ \\
com o oxidante por poço de injeção & 10 & 10 & $\%$ \\
$\mathrm{n}_{\mathrm{e}}=$ porosidade efetiva & 0,30 & 0,30 & $\mathrm{~g} \mathrm{KMnO} / \mathrm{kg} \mathrm{solo}$ \\
SOD $=$ demanda de oxidante do solo & 2.748 & 22.685 & $\mathrm{~kg}$ \\
$\mathrm{M}_{\mathrm{o}}=$ massa de oxidante & 0,44 & 0,50 & $\%$ \\
$\mathrm{C}_{\mathrm{o}}=$ concentração do oxidante & 624.655 & 4.536 .960 & $\mathrm{~L}$ \\
$\mathrm{~V}_{\text {as }}=$ volume de água para solução & & & \\
\hline
\end{tabular}


Durante as atividades de injeção, que se prolongou por duas semanas, a concentração de $\mathrm{KMnO}_{4}$ foi acompanhada nos 14 poços de monitoramento existentes na área foco do teste-piloto. Como resultado, a Figura 3 mostra a evolução da presença de $\mathrm{KMnO}_{4}$ observada nos poços de monitoramento durante o período de injeção e nos monitoramentos de desempenho subsequentes.

Observando a presença de permanganato de potássio nos poços de monitoramento na área do teste-piloto, foi possível avaliar o raio de influência que o oxidante pôde atingir, tanto durante o período de injeção quanto nos monitoramentos de desempenho em um, três e seis meses após a injeção. Após dois dias de injeção, identificou-se permanganato de potássio em poços de monitoramentos distantes 7,5 $\mathrm{m}$ do poço de injeção mais próximo e, após um mês, sua abrangência foi observada em poços instalados até $12 \mathrm{~m}$ de distância do ponto injetado.

Para avaliar os resultados da diminuição das concentrações de contaminantes organoclorados neste teste-piloto, são apresentadas na Figura 4 as delimitações das plumas de 1,1-DCE em dois períodos de tempo, respectivamente,

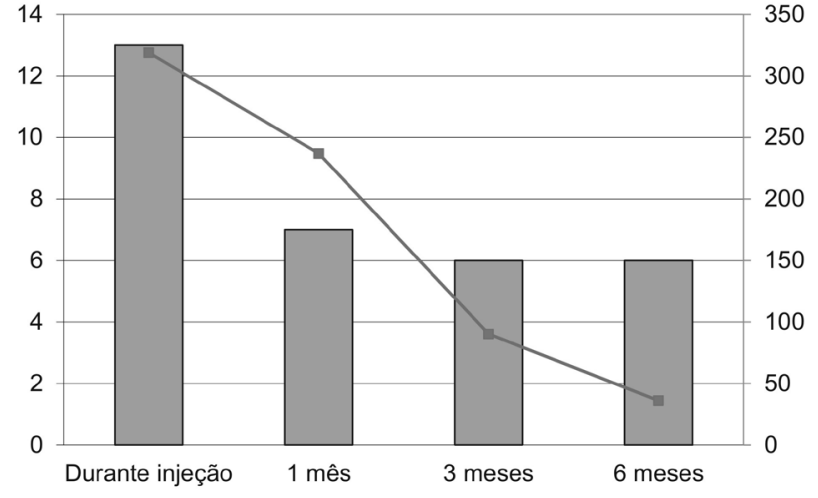

Monitoramentos durante e após injeção

$\square$ Número de poços de monitoramento com presença de $\mathrm{KMnO}_{4}$

- Concentração média de $\mathrm{KMnO}_{4}(\mathrm{ppm})$

Figura 3. Presença de $\mathrm{KMnO}_{4}$ nos poços de monitoramento durante e após o período de injeção do teste-piloto.

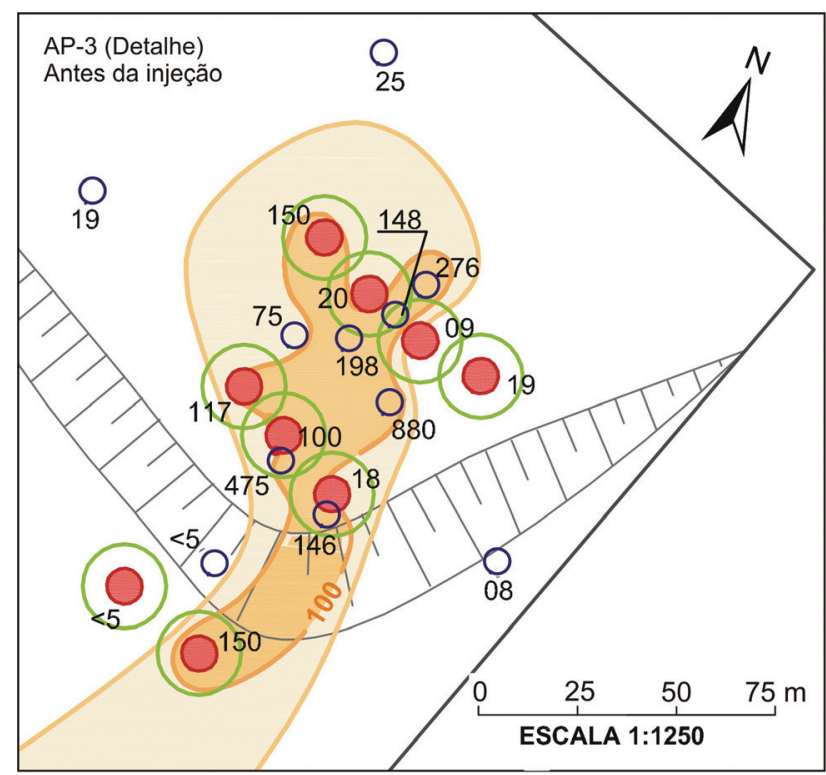

LEGENDA

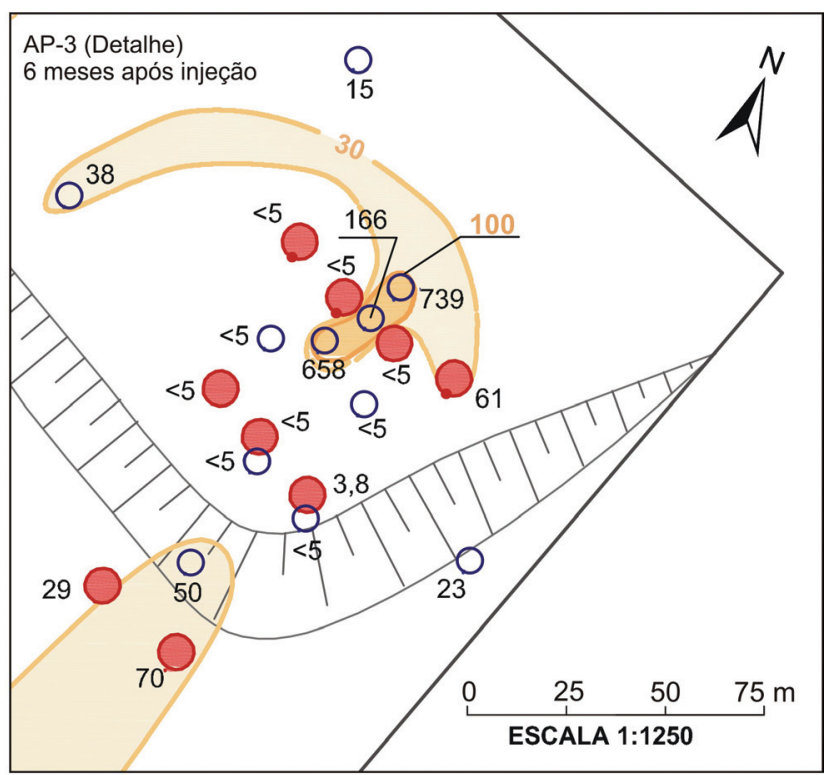

1,1 - DCE (ug/L)

$30-100$

$>100$

Raio de Influência dos Poços de Injeção - 6 m

150 Concentração (ug/L)

Figura 4. Detalhe da área tratada no teste-piloto e raios de influência calculados em $6 \mathrm{~m}$ (situação em maio de 2005). 


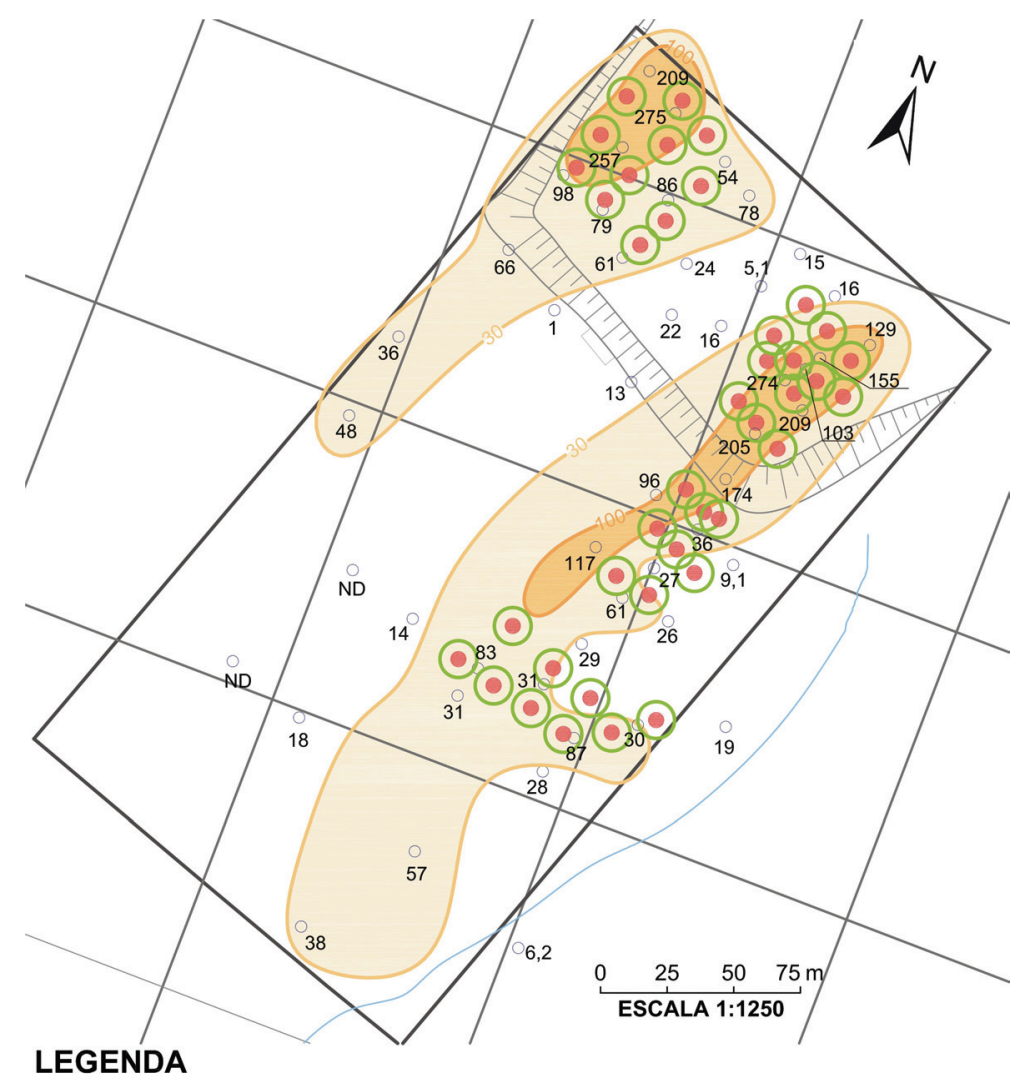

Poço de Injeção

Poço de Monitoramento

Raio de Influência dos Poços de Injeção - 6 m

274 Concentração (ug/L)

\section{1,1 - DCE (ug/L)}

$30-100$

$>100$

Figura 5. Localização dos poços de injeção previstos para a remediação da área até concentrações inferiores à meta de remediação.

antes e seis meses após a injeção. Na Figura 4 são apresentados também a localização dos poços de injeção e seus respectivos raios de influência, previstos inicialmente em $6 \mathrm{~m}$.

Considerando a área de influência de $818 \mathrm{~m}^{2}$ do sistema de injeção do teste-piloto, uma espessura média de zona saturada de $7 \mathrm{~m}$, uma porosidade total de $30 \%$ e uma concentração média de 1,1-DCE de $142 \mu \mathrm{g} / \mathrm{L}$ antes da injeção de $\mathrm{KMnO}_{4}$ e de $94 \mu \mathrm{g} / \mathrm{L}$ após esta injeção, estima-se que a aplicação do $\mathrm{KMnO}_{4}$ reduziu a massa de 1,1-DCE de 1,88 para $0,86 \mathrm{~kg}$ após seis meses de injeção, atestando a eficiência da aplicação do método em escala de campo. Embora a maior parte dos poços de monitoramento tenha apresentado diminuição nas concentrações de 1,1-DCE, alguns tiveram aumento em suas concentrações (Figura 4). Uma possível explicação para este fenômeno é que o $\mathrm{KMnO}_{4}$ pode ter sido totalmente consumido na oxidação da matéria orgânica sólida em alguns locais, liberando para a água o 1,1-DCE anteriormente adsorvido.

\section{Injeção do oxidante em escala de remediação}

Os resultados do teste-piloto foram considerados satisfatórios e, juntamente com aqueles dos demais testes realizados na área, houve embasamento prático para a aplicação 
da ISCO em toda a área do aquífero impactado. Assim como realizado no teste-piloto, os cálculos considerando dados específicos para a área e apresentados na Tabela 2 foram utilizados no dimensionamento do sistema de remediação. Portanto, a massa de oxidante ideal para a remediação da área impactada de forma a alcançar concentrações de 1,1-DCE inferiores à meta de remediação foi de 23 toneladas. Com concentração da solução estimada em $0,5 \%$, foi necessário o volume de $46.000 \mathrm{~m}^{3}$ de água. Hidrômetros foram instalados em todos os poços de injeção para que se pudesse verificar o volume de solução injetada. Ao final da injeção, observou-se que os poços de injeção receberam entre 4 e $175 \mathrm{~m}^{3}$ de solução. $\mathrm{O}$ valor médio injetado foi de $118 \mathrm{~m}^{3}$ por poço de injeção.

A instalação dos poços de injeção foi focada nos locais onde, historicamente, foram observadas as maiores concentrações de 1,1-DCE. Logo, 17 dos 58 poços de monitoramento instalados na área poderiam não estar ao alcance do oxidante injetado. A Figura 5 apresenta o delineamento da pluma de contaminante identificado anteriormente às atividades de remediação, bem como o raio de influência de injeção de $6 \mathrm{~m}$ inicialmente previsto.

A locação dos poços de injeção nos centros de ambas as plumas visou ao abatimento de massa do contaminante, onde as concentrações encontravam-se superiores à meta de remediação. Uma linha de poços de injeção foi adicionalmente colocada na porção jusante da pluma de maior extensão, objetivando evitar o caminhamento dos contaminantes da área mais impactada para além dos limites investigados.

Uma das vantagens do uso do permanganato de potássio como alternativa de remediação de uma área contaminada por compostos organoclorados é o fato deste possuir maior tempo de meia-vida e, portanto, maior capacidade de oxidar os contaminantes por mais tempo, quando comparado a outros oxidantes como, por exemplo, o peróxido de hidrogênio. Neste trabalho, a persistência do $\mathrm{KMnO}_{4}$ no aquífero foi observada durante as atividades de monitoramento do desempenho, com concentrações médias da ordem de $5 \mathrm{mg} / \mathrm{L}$, detectadas na maior parte dos poços de monitoramento mesmo após 22 meses dos trabalhos de injeção (Figura 6), em que pese a ocorrência de diluição provocada pelos eventos naturais de recarga do aquífero.

Embora o raio de influência inicial de injeção esperado fosse de $6 \mathrm{~m}$, o permanganato de potássio foi observado em poços de monitoramento distantes em até $18 \mathrm{~m}$ em pelo menos um poço de injeção, o que resultou em uma maior eficiência. A Figura 7 indica que, 22 meses após a injeção, a maior concentração detectada foi de $309 \mu \mathrm{g} / \mathrm{L}$.

Quando comparadas as concentrações médias entre os períodos anterior e posterior à implantação do sistema de remediação, respectivamente, 200 e $24 \mu \mathrm{g} / \mathrm{L}$, calculou-se que houve uma redução da massa de contaminante de

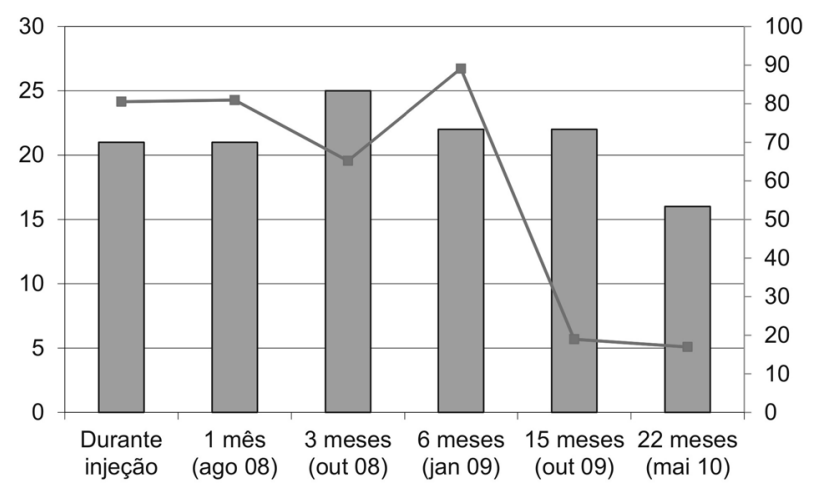

Monitoramentos durante e após injeção

$\square$ Número de poços de monitoramento com presença de $\mathrm{KMnO}_{4}$

- - Concentração média de $\mathrm{KMnO}_{4}(\mathrm{ppm})$

Figura 6. Presença de $\mathrm{KMnO}_{4}$ nos poços de monitoramento durante e após o período de injeção em toda a área.

15,53 para 1,81 kg. Os poços de monitoramento instalados na base do aquífero freático apresentaram diminuição nas concentrações de 1,1-DCE até níveis inferiores ao limite de $30 \mu \mathrm{g} / \mathrm{L}$, estabelecido pelo órgão ambiental, ou passaram a ser não quantificados nas análises químicas.

\section{CONCLUSÕES}

Com base no acompanhamento dos resultados analíticos após a aplicação da ISCO em toda a área impactada, entende-se que o oxidante entrou em contato direto com o contaminante no foco da remediação, principalmente devido ao fluxo advectivo da água subterrânea, visto que o oxidante foi identificado em poços de monitoramentos existentes até $18 \mathrm{~m}$ de distância. Isso pode ser confirmado pela diminuição da massa de contaminante de 1,1-DCE, disponível na zona saturada do aquífero e das concentrações deste mesmo composto até a meta de remediação calculada, com exceção de um único ponto.

A remediação também foi efetiva no nível inferior do aquífero, já que o oxidante injetado pelos poços de injeção de seção filtrante totalmente penetrante atingiu a água subterrânea dos poços de monitoramento, instalados no topo da camada de aquitarde, e resultou em redução nas concentrações de 1,1-DCE.

Resultados dos testes realizados em campo e em laboratório mostraram a possibilidade de uma baixa dosagem do oxidante ser suficiente para a diminuição da contaminação existente. Fato que foi confirmado pelos valores analíticos de 1,1-DCE observados ao longo das campanhas de monitoramento realizadas para avaliar a real eficiência do permanganato de potássio. É importante observar que 

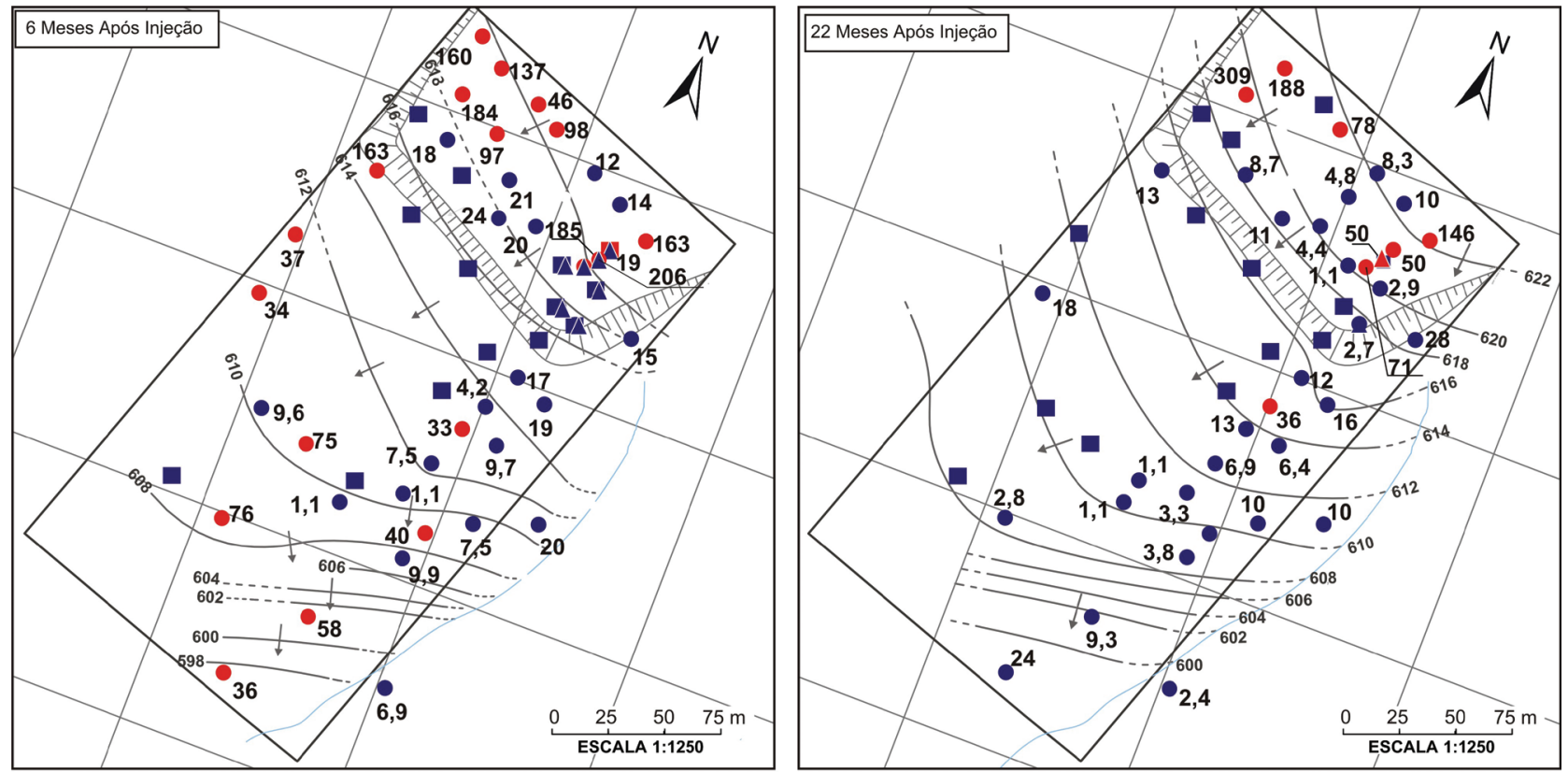

LEGENDA

Poço de Monitoramento Raso com Concentrações Acima dos Limites Orientadores

Poço de Monitoramento Raso com Concentrações Abaixo dos Limites Orientadores

Poço de Monitoramento Intermediário com Concentrações Acima dos Limites Orientadores

Poço de Monitoramento Intermediário com Concentrações Abaixo dos Limites Orientadores

Não Detectado

103 Concentração $(\mu \mathrm{g} / \mathrm{L})$

$596--$ Linhas Equipotenciais (metros)

$\longleftarrow$ Direção de Fluxo da Água Subterrânea

Figura 7. Comparação entre os resultados de monitoramento de desempenho da ação do $\mathrm{KMnO}_{4}$ em 6 e 22 meses após as atividades de injeção em toda a área.

a efetividade da aplicação desta tecnologia de remediação neste caso específico ocorreu especialmente pela associação de alguns fatores, dentre eles: o modelo conceitual hidrogeológico da área ser relativamente simples, em que o aquífero apresenta uma baixa heterogeneidade geológica relativa no local, além de condutividade hidráulica adequada; as concentrações iniciais do composto alvo serem relativamente pequenas, com uma possibilidade mínima de ocorrência de fase residual do organoclorado no solo; os recursos terem sido utilizados para a completa delimitação horizontal e vertical do meio impactado e a correta aplicação da metodologia ISCO, tanto na sequência de atividades como nos quantitativos.

O modelo conceitual hidrogeológico simples e as baixas concentrações do composto alvo contribuíram para que a remediação fosse atingida num prazo relativamente curto, situação esta que se aproxima mais à exceção do que à regra. Circunstâncias em que o meio geológico apresenta maior predominância de finos e concentrações de contaminantes mais elevadas, que levam à suspeita de existência de fase residual, são bem mais favoráveis à ocorrência de diminuição da permeabilidade original do aquífero devido à precipitação de $\mathrm{MnO}_{2}$ secundário e de difusão reversa a partir de camadas de baixa permeabilidade, favorecendo a ocorrência frequente de repiques de contaminação após a aplicação do oxidante químico, elevando sobremaneira o tempo de remediação, muitas vezes tornando-a ineficaz.

Sobre a aplicação da metodologia ISCO, é fundamental que recursos em ensaios técnicos de campo e de laboratório, além da instalação de poços de injeção compatíveis 
com o raio de influência específico do local sejam empreendidos em projetos semelhantes. Neste sentido, este trabalho contribui apresentando os procedimentos metodológicos para a condução de tais ensaios técnicos, especialmente nas escalas de ensaio-piloto e de remediação, e os fatores para os quais se deve dar atenção à correta condução destas atividades.

\section{AGRADECIMENTOS}

Os autores agradecem à empresa ERM Brasil Ltda. pelo apoio à primeira autora na realização do curso de pós-graduação, pela estrutura fornecida para a execução dos trabalhos de campo e pela permissão de utilização dos dados para a realização deste trabalho.

\section{REFERÊNCIAS}

ABNT - Associação Brasileira de Normas Técnicas. Poços de monitoramento de água subterrâneas em aquíferos granulares - NBR 15495-1:2007. ABNT, 2007, 33 p.

ASTM - American Society for Testing and Materials. D7262-10 Standard test method for estimating the permanganate natural oxidant demand of soil and aquifer solids. ASTM International, USA, 2010, 5 p.

BARBOSA, O; GOMES, F.A. Pesquisa de petróleo na bacia do Rio Corumbataí, Estado de São Paulo. Boletim da Divisão de Geologia e Mineralogia, Rio de Janeiro, DNPM, n. 171, p. 1-40, 1958.

CRIMI, M. L.; SIEGRIST, R. L. Geochemical effects on metals following permanganate oxidation of DNAPLs. Ground Water, v. 41, n. 4, p. 458-469, 2003.

DOE - Department of Energy. In situ chemical oxidation using potassium permanganate. Piketon, Ohio, United States (DOE/EM-0496), 1999.
HØNNING, J. Use of in situ chemical oxidation with permanganate in PCE-contaminated clayey till with sand lenses. Ph.D. Thesis - Institute of Environment and Resources, Technical University of Denmark, 2007.

HU, G. J.; CHOU, R. Pilot test using potassium permanganate solution for VOCs-impacted groundwater cleanup. Battelle Third International Conference on Remediation of Chlorinated and Recalcitrant Compounds, Monterey, CA, 2002.

IPT - Instituto de Pesquisas Tecnológicas. Mapa geológico do Estado de São Paulo. São Paulo, IPT, 1981, v. 1. Escala 1: 500.000 .

PANKOW, J. F.; CHERRY, J. A. Dense chlorinated solvents and other DNAPLs in groundwater. Waterloo Press, Ontario, Canada, 1996. 525 p.

SEOL, Y.; ZHANG, H.; SCHWARTZ, F. W. A review of in situ chemical oxidation and heterogeneity. Environmental and Engineering Geoscience, v. 8, n. 1, p. 37-49, 2003.

SOARES, P. C. O limite glacial-pós-glacial do Grupo Tubarão no Estado de São Paulo. Anais da Academia Brasileira de Ciências, Rio de Janeiro, v. 44, p. 333-341, 1972.

SUTHERSAN, S. S.; PAYNE, F. C. In situ remediation engineering. CRC Press, Taylor and Francis Group, Boca Raton, FL, 2005, 511 p.

USEPA - United States Environmental Protection Agency. Monitored natural attenuation, United States (EPA/510/R-04-002), 2004.

USEPA - United States Environmental Protection Agency. In situ chemical oxidation. Engineering issue. EPA/600/R-06/072. 2006. Disponível em: <http://www. epa.gov/ada/gw/isco.html $>$. Acesso em: 01.03.2012. 